\title{
SELF-DEVELOPMENT MODEL FOR IMPROVE LEADERSHIP SKILLS OF EXECUTIVES MANAGERS: COMPARISON STUDY IN TWO DIFFERENT COUNTRIES - SRI LANKA AND CHINA
}

\author{
V.Sivalogathasan \\ Department of Management Studies, \\ The Open University of Sri Lanka, Nawala, Sri Lanka \\ vsiva@ou.ac.lk
}

\begin{abstract}
In order to understand the importance of human resources management and to see how it is influenced by cultures and nations, this study is to compare in two really different countries such as Sri Lanka and China. The transition towards a socialist marketoriented economy has presented many challenges to both China and Sri Lanka. One of the key human resource challenges has been to develop business leadership skills in a flexible, timely and cost-effective manner. This paper focuses on the self-initiated approach to professional development that has been introduced by managers at a grassroot level to improve business leadership (referred to as self-development). Given the limited research on self-development in China and Sri Lanka, the intention of this paper is to enrich understanding of why managers in a complex and dynamic transitional environment undertake self-development activities. The findings of this study suggest that there is no 'one-size-fits-all' paradigm to understand self-development across contexts. First, the western model of leadership competencies at the different management levels do not necessarily fit the needs that managers are targeting in their self-development activities in China and Sri Lanka. Second, despite some similarities between China and Sri Lanka, the Chinese managers were more interested in technical leadership skills than the Sri Lankan managers whose self-development foci were centered on improving their moral standards. Such differences highlight each country's stage of economic and social development while reinforcing the influence of contextual factors. It also suggests that self-development is best understood as a process within a specific context.
\end{abstract}

Keywords: human resource management, leadership, self-development,

\section{Introduction}

The transitional economies of China and Sri Lanka have achieved remarkable growth since they separated from the old-style command economy and embarked on a transformation towards a socialist market-oriented economy. While economic growth elsewhere has largely slowed, China has maintained a growth rate above 7 per cent in recent years (World Bank 2013). Additionally, Sri Lanka has maintained its annual growth rate of 6 to 7 per cent for more than two decades and is becoming a key player in Southeast and South Asia. As China and Sri Lanka continue to advance and grow, having the right managers in place with the right leadership skills has never been so important.

However, China and Sri Lanka's rapid economic growth, coupled with continuing reforms, means that developing leaders that can cope and thrive in a growing but volatile market has become a pressing imperative. For the Chinese sector to prosper, the recent National program 
for medium and long-term talent development (2010-2020) proposes to increase the number of competent managers to 35 million by 2015 and to 42 million by 2020 (GPRC 2010). For Sri Lanka, the ubiquity of insufficient business leadership skills has also been acknowledged. In The five-year socio-economic development plan (2011-2015), the Sri Lanka government emphasizes the necessity to develop leaders in order to maintain economic growth after end of civil war.

For both countries, a short history of exposure to an open market has meant that there is a lack of experience in predicting, training and developing the leadership skills that are compatible with a market-oriented economy. Likewise, the research and practice of formal training programs that improve business leadership are underdeveloped (Borgonjon \& Vanhonacker, 1994; Li \& Sheldon, 2010; Zhu \& Warner, 2013). The existing programs are not comprehensive enough to develop the required business leadership skills - as they are often theory-driven and do not align with organizational needs (Benson, Gospel \& Zhu, 2013; Goodall \& Warner, 2009).

Furthermore, they are general in nature and there is little customization to suit managers' learning preferences; or they are too costly and inhibit organizational investment in formal professional development programs (Edwards \& Phan, 2013). Increasingly, research has emerged with a focus on the role of the individual, acknowledging that individuals should undertake and control their own learning efforts and development process, without being directed by formal job requirements (Boyce,
Zaccaro \& Wisecarver, 2010). Referred to as self-development, this approach fits with a new breed of managers, who understand the need for continued professional development and take responsibility for managing their own career paths (Garavan et al. 2002).

The possibility that leaders can improve their business leadership through a self-initiated approach broadens the scope of leadership development studies. Furthermore, it highlights the need for individual examination in a transitional economy and consideration of whether leaders are passive recipients of state policies or whether they proactively respond to changing environments. The extant literature on self-development in China and Sri Lanka is limited and research in this area has predominately focused on self-development in the workplace as a largely western phenomenon (Orvis \& Langkamer, 2010; Reichard \& Johnson, 2011). Moreover, China and Sri Lanka do not necessarily share the same characteristics as the countries where these prior studies have been conducted. Undertaking a learning process of any kind to develop leadership skills is informed by a cognitive process whereby individuals draw upon their worldview and sense of self to develop cues; importantly such a cognitive process differs within a specific context (Peterson \& Wood, 2008).

Therefore, a qualitative approach is used to investigate this under researched area. The research focuses on some key questions:

1 Why do managers in a transitional economy such as in China and Sri Lanka adopt selfdevelopment strategies to build their leadership competencies? 
2 What aspects of leadership skills do Chinese and Sri Lankan managers target in their selfdevelopment activities?

3 Why do they target these activities?

By posing these questions and using qualitative methods, we present a rich account of leadership self-development in China and Sri Lanka. In order to reveal different perspectives, we selected managers from firms with different ownership systems, namely state owned enterprises (SOEs), domestic private enterprises (DPEs) and foreign investment enterprises (FIEs) with total of 32 targets in China and 40 targets in Sri Lanka.

The paper is structured as follows. First, we review China and Sri Lanka's transition in light of their economic reforms and shifting social values. We provide a review of changes in the leadership landscape and the different approaches of each country to learning and development. Second, we review the relevant literature and the theoretical concepts associated with the self-development process. Third, we outline the methods of data collection and analysis and present the interview results. Fourth, we discuss the findings by focusing on the role of the individual in a transitional economy, comparing and contrasting China with Sri Lanka and with mainstream western literature. Finally, the limitations of the study are identified and the paper is concluded with indications of where further studies could be developed to further develop this area of research.

\section{China and Sri Lanka in transition}

China embarked on the transition en route to market orientation, termed economic reforms and opening-up, in 1979 (Warner, 2009). Seven years later, Sri Lanka launched its own economic renovation, namely open economy, with the goal of creating an 'open marketoriented economy' in 1977. Both countries have adopted an incremental approach to transform their economies from a central planning system to a socialist and market-oriented economy involving a mix of organizational ownerships (i.e. SOEs, DPEs, and FIEs). In the past decade, both China and Sri Lanka have achieved remarkable economic growth as indicated by their GDP. For example, China's GDP increased from US\$2269 billion in 2006 to US\$9491 in 2014 (NBSC, 2014). Sri Lanka's GDP increased from US\$24 billion in 2006 to US\$67 in 2014 (CBSL, 2014).

Beyond the growth that has taken place in the economic realm, managers in China and Sri Lanka now find themselves exposed to a range of challenges. They have to cope with previously unheard of job insecurity on the one hand and balance normative values on the other (Warner, 2009). These normative values come from traditional cultures, in particular Confucianism and Buddhism, in both countries. Scholars have observed that Confucianism and Buddhism are integral to the traditional cultures of East and South Asia and pervasive in the everyday life of individuals (Wang et al. 2005). They also come from socialist ideologies in China and Sri Lanka and here we mainly refer to socialist egalitarianism with party control (Warner et al. 2005). These different cultural values, including socialism, confucianism, buddhism, and western capitalism, have created a more complex, ambivalent and changeable context 
than in the western developed world.

On the face of it, the transition towards a market-oriented economy of Sri Lanka exhibits much in common with that of China. However, these commonalities manifest themselves differently due to Sri Lanka's unique historical background and developmental trajectory. Sri Lanka's history is marked by repeated invasion from the Indians, Europe such as Poduges, Dutch, and British people. The contact and interaction with these often powerful groups leads to, first, an absorption of many aspects of the imported cultures; second, continual resistance - to the point of total denial - of Sri Lankan local culture; and third, a sense of distinctiveness and pride in Sri Lankan people. It is yet to be understood how Confucianism, Buddhism, socialism and capitalism 'with Chinese and Sri Lanka characteristics' interact with each other and how their interactions influence a manager's undertaking of selfdevelopment activities in these two countries.

\section{Changing leadership landscape}

The transformation of a country is a challenging process that creates a need to upgrade its workforce and builds up pressure to improve the quality of management (Xie, Zhu \& Warner, 2013). On the demand side of the labour market, leadership skills acquired in the old-style planned economy become insufficient when dealing with new challenges, brought about by industrial transformation and an increased engagement with external international markets.

For China, in the previous state-planned economy, the ideology of Mao - the founder of New China - laid the cornerstone for selecting and evaluating leaders in government, enterprises and the military. Mao's thoughts on the essential requirements for leadership competencies are captured in the slogan you hong you zhuan, meaning 'both red and expert, or both socialist-minded and professionally proficient' (Li 1995, 544). Managers were often assigned by government agencies based on their political orientation but did not necessarily have the appropriate knowledge or skills required by enterprises.

With the deepening of economic reforms, and in response to market pressure in China, managers in SOEs have more economic decisionmaking powers and are starting to become fully accountable for production outputs, administration and management activities (Zhu, Webber \& Benson, 2010). Furthermore, employees' roles have now been clarified by a range of reforms that were implemented in the 1980s and that established a management engagement system, a labour contract system and a floating wage system. Increasingly, the leadership role in SOEs and other types of Chinese organizations has evolved from its initial symbolic and ideological status to being an increasingly functional role (Zhu, Webber \& Benson, 2010).

As for Sri Lanka, the leadership requirements in its previously centrally planned economy also focused on an individual's political orientation over their management abilities. The management in Sri Lanka's SOEs during the pre-reform period came from four sources: the party leadership, management, union representatives and youth representatives - with the party leadership being the most important indicator in determining success. Managers in 
SOEs enjoyed the 'work for life' system which offered secure employment and a salary paid directly by the government. Since the mid1977s, Sri Lanka has been motivated by an urgent need to improve the legal institutional environment and to facilitate a market economy. The 1980 Labour Code established clear legal responsibilities associated with employment relations and formalised issues related to labour contracts, collective working agreements, recruitment and dismissal, union and compensation structure. A revised Labour Code took effect in 2013 with further reforms related to labour contracts, work hours, internal labour rules and working conditions (ILO, 2012). This legislation has nurtured market orientation and requires the updating of leadership competencies in accordance with emerging challenges. Leaders in SOEs have become more autonomous and are expected to act quickly and strategically to market changes, rather than simply responding to production targets that are administratively set up by the state. Managers in Sri Lanka today - either in SOEs, DPEs or FIEs - operate in an economy where the Communist and market ideology emphasizes a balance between economic prosperity and the workers' well-being (Edwards \& Phan ,2013).

\section{Approaches to training and development}

On the supply side of the labour markets of China and Sri Lanka, people in organizations do not have access to high-quality management and leadership-related training. The provision of training is minimal in many Chinese companies, largely due to a lack of resources and the belief that managers have little strategic impact on the success of a business (Rowley,
2010). In Sri Lanka, the majority of in-demand jobs, in particular in FIEs, are aimed at the lower level of the labour structure where there is an emphasis placed on technical skills. The education that most people receive has suffered largely from a lack of resources, substandard teaching, a shortage of facilities and ineffective training programs.

In the pre-reform period, managers in SOEs in China were sent to the party school on a regular basis to study Marxism and party policies. Conversely, in the post-reform period, organizations seldom pay for the provision of training programs. Consequently, the obligation to learn and develop leadership skills that are compatible with the market economy has largely shifted towards being a responsibility of the individual. Nonetheless, the emphasis on continuous learning is not a new concept for individuals in either country. Confucianism lays a traditional foundation of thought and behaviour that promotes striving for intellectual nourishment, with an emphasis on long-term orientation and hard work. It does not share the same characteristics that shape the scholarly investigation of self-development in the mainstream literature (Beckett \& Hager, 2002).

The approach of Confucianism towards learning and development relies on its central underpinning ren (benevolence) which, in turn, points to continuous striving for self-perfection (Ren, Zhu \& Warner, 2011). Confucius' purpose of learning is not about finding the absolute truth, or generating knowledge, but it is moral in nature $(\mathrm{Li}, 2002)$. Hence, the characteristic of the mental process for approaching learning 
and development among Chinese and Sri Lanka people embraces a higher tolerance of ambiguity and elasticity than typical western approaches (Lin \& Ho, 2009). This lends support to the suitability of taking a qualitative approach to this research so as to explore the key elements within a China and Sri Lanka paradigm.

\section{The self-development process}

Many theories have been developed to explain human action. However, they differ in the conceptualization of the nature of human action. This, in turn, influences the mechanisms of human functioning on which scholars focus and the analytic tools they use for scientific enquiry (Bandura, 2013). Self-development is the deliberate development of leadership skills, initiated, guided and controlled by managers over an extended period of time. It can be formal or informal, on-the-job or outside working hours. The key element is that the individual takes responsibility for identifying and directing the why, what, where, when and how of their development (Boyce, Zaccaro \& Wisecarver, 2010). This process is not undertaken ad hoc, but is purposive in nature - in that people affect their own actions by analyzing, encoding and responding to the features of the context.

The deliberate and self-regulating properties of self-development are particularly important in transitional economies, such as China and Sri Lanka, where people have to interpret and respond to the multiple changing contexts experienced simultaneously with different economic, social, and organizational perspectives. According to social cognitive theory, individuals, their context and action are engaged in a triadic-reciprocal causal relationship (Bandura, 1986). People's selfdevelopment is influenced by the cognitive tools they use to interpret the world. These cognitive tools are informed and reinforced by the social structures and practices of the specific contexts in which people work and live (Nisbett, 2003).

By applying this theoretical paradigm to the current research, organizations constitute the immediate environment in which managers operate. Their attitudes, defined as the values and norms shared within the organization, serve as a reference point for appropriate action and behaviour to enhance leadership development (Dragoni, Tesluk \& Oh, 2009; Straub, 2012). Organisational attitudes that emphasise and support self-development contribute to recognition of its importance. This can lead to a consensus and synergy in taking proactive steps to develop leadership skills. Furthermore, it can lead to a higher level of intellectual curiosity for learning and the willingness to make adjustments in outlook and behaviour in a self-initiated way (van Grinsven \& Tillema, 2006).

Self-development as it is manifest in the workplace has forward-thinking properties (Reichard \& Johnson, 2011). In this sense, people's attitudes, perceptions and values around work and career progress influence their understanding and actions with regard to selfdevelopment (Boyce, Zaccaro \& Wisecarver, 2010). This suggests that a manager who establishes a central self-image and identifies with being a leader will seek out learning opportunities to maintain belongingness with 
the 'leader' group (Haslam, 2004). It also suggests that, by internalizing work-relevant values and norms, managers are more likely to undertake discretionary effort to embark on development activities (Hurtz \& Williams, 2009).

The way that contextual factors and work attitudes transform into self-development action builds upon the cognitive process associated with the self-regulatory mechanisms (Bandura, 2013; Wood, 2005). These mechanisms, as applied to the learning and development process, are termed learning readiness (Avolio, 2004). This readiness operates through a function of comparing one's leadership skills against certain performance standards and evaluating the individual responsibility against the organisational responsibility to initiate learning (Avolio \& Hannah, 2009). The resulting product of learning readiness may then involve a perceived need for development and a higher sense of personal responsibility which, in turn, provides direction for goalsetting related to leadership improvement (Day, Harrison \& Halpin, 2009).

\section{Data collection and analysis procedures}

The same data collection methods and interview protocols were used within both countries during the fieldwork conducted in China and Sri Lanka. Both countries have a diversified ownership system, represented mainly by SOEs, DPEs and FIEs. The ownership of firms is a major proxy for delineating the heterogeneity arising from the interplay of old and new institutional forces in transitional economies. To maximize the likelihood of revealing different perspectives, this study covered a range of firm ownership types including SOEs, DPEs and FIEs. Within each country, six companies per ownership type were randomly selected and their senior human resource (HR) managers contacted for access to their managers. After obtaining consent, an e-mail was sent to the focal managers inviting them to participate in the interviews. The e-mail contained a brief explanation of the research project written in plain language (in English and Chinese/Sinhala/Tamil) and emphasized that participation was completely voluntary and that confidentiality would be protected.

In total, 30 interviews were conducted in China and 30 interviews in Sri Lanka, all on a oneto-one basis. The interview questions centered on the key themes of this paper - including why managers undertake self-development, the personal and organizational enablers of self-development and the types of leadership competencies managers target in their selfdevelopment activities. These interviews enable us to develop a holistic understanding of the phenomena under study. As the fieldwork in Sri Lanka was conducted before the fieldwork in China, the feedback obtained from Sri Lankan managers informed a minor revision of the interview questions used in China. In particular, Sri Lankan interviewees constantly referred to traditional wisdom for effective leadership and for personal development. We therefore added a research question during fieldwork in China asking participants to provide the local traditional slogan, old sayings or idioms that guided their self-development activities.

During the fieldwork in Sri Lanka and China, we interviewed managers from a wide range of backgrounds, not only related to the ownership 
of their organizations, but also related to their demographic variables (see Table 1). Sri Lankan and Chinese participants ranged in age from 30 to 55 , with the majority being in their mid-35s and $45 \mathrm{~s}$. Their tenure with the company ranged from 3 to 15 years among the Chinese and from 3 to 30 years among the Sri Lankan. Among the 60 managers interviewed, 31 held a Bachelor's degree and Diploma, 14 had obtained a Masters qualification and 6 had completed a $\mathrm{PhD}$ degree, while only 9 interviewee had not attended university. Additionally, the managerial roles performed by the Chinese and Sri Lankan participants varied and included people who worked in sales, information technology (IT), HR and consultancy.

The analysis procedures involved assigning codes to selected portions of data at different levels of conceptual abstraction (Yin, 2011). These initial codes resembled the original text and ranged from simple concepts - such as survival and tradition - to more detailed descriptions - such as the difficulty in developing ethical leadership, how to be seen as a role model to subordinates, and employers imposing high expectations on them. We then proceeded to a higher set of codes that categorized the initial codes and analyzed the emerging patterns. This approach allowed for comparison of the data from China and Sri Lanka as stand-alone entities as well as providing the capacity to analyses more general patterns.

\section{Findings}

Chinese and Sri Lankan managers agreed that the emphasis on being successful, that is, through maintaining a formal leadership position, is reinforced by the normative value: 'bringing prestige and honour to one's family and clan'. This value is less about personal ego and more about how one contributes to the pride of the collective group he/she belongs to. Managers in China and Sri Lanka commented that a leadership position is deemed to be of high status and considered as a pathway to a successful life. Therefore, for these managers, adopting continued learning and development patterns increased the respect they had from fellow workers.

However, Chinese managers in particular made reference to the pressure on survival in the labour market and their increased vulnerability and job insecurity. A majority of interviewees felt vulnerable due to the: 'enormous pressure and drastic changes' and 'the high expectation imposed by companies' (interviewees from a DPE in China); 'organizational pressure to meet unrealistic goals' and 'excessive workloads' (interviewees from a FIE in China). To address these challenges, Chinese managers turned to self-reliance as a solution. They constantly examined their performance and sought to selfdevelop certain skills that could contribute to personal achievements in the workplace more rapidly.

Although Sri Lanka has also embarked on market-oriented reforms, the way in which market competition intensifies their work environment is different to that of China. As an interviewee from a FIE in Sri Lanka observed: 'You just can't fire a person freely in Sri Lanka, regardless of the firm ownership. It breaks the social norm here and ruins the relationship.' Maintaining the identity of a leader through 
Self-Development Model for Improve Leadership Skills of Executives Managers: Comparison Study in Two Different Countries - Sri Lanka and China

Table 1 Profile of interviewees and firms

\begin{tabular}{lcc|lrc}
\hline Sample Profile & China & Sri Lanka & Firm Profile & China & Sri Lanka \\
\hline Gender & & & Firm ownership & & \\
Male & $15(50 \%)$ & $24(80 \%)$ & Private & $14(47 \%)$ & $16(53 \%)$ \\
Female & $15(50 \%)$ & $06(20 \%)$ & Government & $05(16 \%)$ & $08(27 \%)$ \\
& & & Entrepreneurs & $11(37 \%)$ & $06(20 \%)$ \\
\hline Age & & & Age & & \\
$20-29$ & 0 & 0 & $1-5$ & $09(30 \%)$ & $03(10 \%)$ \\
$30-39$ & $10(33 \%)$ & $08(27 \%)$ & $6-15$ & $12(40 \%)$ & $05(17 \%)$ \\
$40-49$ & $11(37 \%)$ & $14(46 \%)$ & $16-25$ & $05(17 \%)$ & $13(43 \%)$ \\
$50<$ & $09(30 \%)$ & $08(27 \%)$ & $25<$ & $04(03 \%)$ & $09(30 \%)$ \\
\hline Experience & & & Size & & \\
$2-4$ yrs & $03(10 \%)$ & $09(30 \%)$ & $<500$ & $14(47 \%)$ & $07(23 \%)$ \\
$5-7$ yrs & $11(37 \%)$ & $10(33 \%)$ & $501-1000$ & $02(07 \%)$ & $06(20 \%)$ \\
$8-9$ yrs & $01(03 \%)$ & $09(30 \%)$ & $1001-2500$ & $04(13 \%)$ & $05(17 \%)$ \\
$10<$ & $15(50 \%)$ & $02(07 \%)$ & $2501-5000$ & $05(16 \%)$ & $03(10 \%)$ \\
& & & $5001<$ & $05(17 \%)$ & $09(30 \%)$ \\
\hline Education & & & Type & & \\
Diploma & $06(20 \%)$ & $03(10 \%)$ & Product & $12(40 \%)$ & $06(20 \%)$ \\
Bachelor & $12(40 \%)$ & $19(63 \%)$ & Services & $10(33 \%)$ & $14(47 \%)$ \\
Master & $08(27 \%)$ & $06(20 \%)$ & Product \& Services & $08(27 \%)$ & $10(33 \%)$ \\
PhD & $04(13 \%)$ & $02(07 \%)$ & & & \\
\hline
\end{tabular}

learning and development was seen as setting a good example to others. For instance, an interviewee from a FIE in Sri Lanka commented: 'Continuous learning is a good virtue and as a leader, I have the responsibility to follow this and be a role model'. This manager's comments were reiterated by the other Sri Lankan interviewees. They viewed work as an essential component of life and had faith in the continual improvement of personal competencies. Performing well in the workplace is part of the educational message that these interviewees had received since childhood and this has constituted the social norm which they follow in their life.

\section{Self-Development as a Response to} the Organizational Attitudes Towards Development

When asked whether their companies invested in effective training and development, the initial comments made by Chinese and Sri Lankan managers focused on their individual dilemmas: while learning needs to occur, they struggled to find the time and energy to engage in learning. In addition, the financial responsibilities of undertaking learning had shifted towards the individual, as an interviewee from a DPE in Sri Lanka commented: 'nowadays we all know we have to look after ourselves to improve our skills and competencies. Companies do not pay for additional training anymore, but 
expect us to be competent at our job.' Given that learning and development has generally been quite limited, it was particularly important that they accurately interpreted the professional development expectations of their companies. For instance, an interviewee from a FIE in China commented on his continual reading of Bloomberg Business Week - a learning initiative that he self-started, self-financed and self-managed. His company had policies and systems in place to encourage, motivate and support individual accountability. This conveyed to him a clear picture of where he was able to go and to what level his leadership skills should be developed.

In the Sri Lankan case, organizational attitudes toward self-development varied. Managers were more likely to undertake self-development when organizations provided a diversified channel to disseminate knowledge and information concerning the latest leadership research output and best practices. In the interview with an interviewee from a SOE in Sri Lanka, there was strong evidence of her company's support for training and development. She was often sent to conferences, forums and seminars with international consulting firms to learn new management theories and models. She stated: I was just a high school graduate when I started working here as a semi-skilled worker. Throughout the past 20 years my company has supported me to study and attend many courses to improve my skills. I now hold an MBA degree and work at a middle management level. This has increased my motivation and desire toward continuous learning and development. This interviewee's quote demonstrates that investment in knowledge and information sharing through employee development might encourage managers to identify gaps around leadership development, which in turn enhances their self-development activities.

\section{The State of Readiness Among Chinese and Sri Lankan Managers}

The concept of learning readiness became clearer as the interviewees constantly used phrases related to developmental needs and personal responsibility. In addition, Sri Lankan interviewees made frequent references to learning for the sake of learning. Among the Chinese participants, there was a strong emphasis on individual employability. The sixth interviewee from a DPE in China previously worked in a SOE in the resource industry - the main industry in which job security and high wages are usually guaranteed. He observed that the conventional way of living and working in the rigidly controlled state sector is now being challenged. Specifically, managers have realized the value in the exchange of knowledge and skills in the labour market. In line with this shift, knowledge and skills are becoming new commodities in these emerging market economies.

While the qualitative data obtained from Sri Lankan managers also demonstrated a similar pattern involving self-awareness, their developmental needs appeared to be more collective in nature, compared to their Chinese counterparts. An interviewee from a SME in Sri Lanka referred to an old Sri Lankan saying study is the endless'. The majority of Sri Lankan interviewees considered this phrase as being integral to their attitude about learning since childhood. This interviewee in Sri Lanka went 
on to say: 'Learning is not an individualist thing here. Look how many young parents send their new-born baby to nursery school. Everyone is doing some sort of learning.' For the Sri Lankan managers, the normative values placed on their continuous striving for self-improvement was the driving force in their personal lives as well as in their career development.

\section{The Demands from Different Cultural Values in Self-Development Activities}

ForChinesemanagers, theprimary consideration in seeking self-development opportunities was to gain a sense of security and to improve their employability. Therefore, developing hard skills that improved their capability to predict the market and enhance their cognitive abilities to cope with the increased complexities at work was highly valued and emphasized. Threats to job security and an enthusiasm for short-term usable leadership skills meant that, in a business environment characterized by constant changes, blocked information flow and underdeveloped institutional infrastructure, the self-development of ethical leadership had been largely marginalized. Ethical reasoning and decision-making was not usually the first self-development priority of the Chinese interviewees. According to them, ethical judgement as it related to leadership was 'not relevant to people's short-term interests' (an interviewee from a FIE in China), 'is harder to develop' (an interviewee from a SOE in China) and 'difficult to evaluate' (an interviewee from a DPE in China) in a business environment in which 'money and profits are what is most valued' (an interviewee from a DPE in China). The above-mentioned characteristics associated with Chinese interviewees were also observed by Sri Lankan interviewees. An interviewee from a DPE in Sri Lanka had a lot of experience in working with people from China and he commented: Chinese managers are very intelligent and quick to learn. They have to be really smart and outstanding to 'stand out' among such a large population back home [in China]. Conversely, I believe that Sri Lankan managers preserve the traditional values more than the Chinese. His comment was also supported by our interviews. Most Sri Lankan managers listed ethical leadership as a priority when undertaking self-development activities. Another interviewee from a FIE in Sri Lanka is from the younger generation and was educated overseas before working as a middle manager in the FIE. Despite his exposure to western cultures, he cited his working motto as 'adopting the principles from our former leaders'. These principles were often reflected by other Sri Lankan interviewees, and involved the ideology of the ruling party (such as party control and egalitarianism - serving the people wholeheartedly) and traditional values (such as contributing to the collective good and maintaining belongingness as a whole).

\section{Discussion}

Given the underexplored nature of the selfdevelopment phenomenon in China and Sri Lanka, this study is important in tackling the central theme of self-development from a contextual perspective. Our findings reflect on the characteristics of complex social settings and provide insights into the underlying reasons and dynamic processes behind the surface of the self-development phenomenon. 
Self-development activities in China and Sri Lanka are growing, but it remains an underspecified phenomenon in HRM studies in both countries. Our qualitative approach builds upon existing literature and offers a rich account of leadership self-development involving managers from different backgrounds. As this study indicates, self-development is not undertaken ad hoc, or isolated from a managers' operating environment. The complex cognitive process of understanding, interpreting, and responding to environmental factors (such as economic reforms, changing social values through organizational expectations and attitudes) to self-development are captured in Figure 1. This provides a meaningful framework for identifying patterns, examining plausibility and enabling conclusions to be drawn concerning the process through which managers perform self-development to improve their leadership skills.

This framework emphasizes the originality of the current research for two primary reasons. First, it highlights the necessity of contextual studies and gives contextual consideration a more holistic perspective. Second, it extrapolates from several properties of self-development, including those grounded in leader identity maintenance, work-related antecedents and organizational influences to the outcomes of developing leadership competencies and setting a role model for others.

\section{Different patterns of self-development in}

\section{China and Sri Lanka}

The findings of this study suggest that the concern for different types of leadership skills valued in self-development activities have implications for theory. The outcome suggests that there is no 'one-size-fits-all' paradigm to understand self-development across contexts. First, the western model of leadership competencies at the different management levels does not necessarily fit those needs that managers are targeting in their self-development activities in China and Sri Lanka.

Second, while we have included the different organizational ownership types, the interview data suggest that the between-country differences count for more than the withincountry differences. Despite some similarities between China and Sri Lanka, the Chinese managers were more interested in technical leadership skills to improve their ability to identify, analyses and predict market trends than the Sri Lankan managers were. This reflects an urgent need for employee survival, influenced by market pressures, competition and a lack of established career structures.

While Sri Lankan managers may encounter similar challenges and pressures on the surface when compared with their Chinese counterparts, their self-development foci have been consistently centered on improving their moral

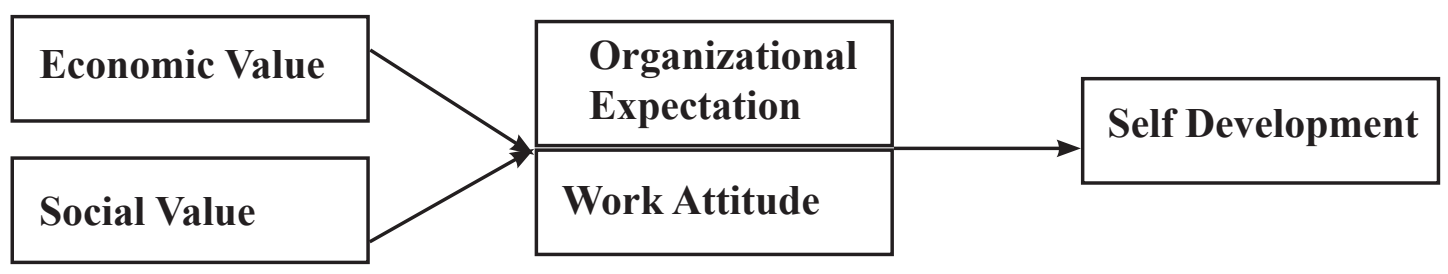

Figure 1 Model of self-development to improve leadership skills 
standards. The emphasis on traditional values and virtues largely explains their relatively higher level of commitment as manifest in the average length of tenure among our sample. Such inconsistencies between our observation and the mainstream literature, between China and Sri Lanka, highlight each country's stage of economic and social development while reinforcing the influence of contextual factors. It also suggests that self-development is best understood as a process within a specific context.

\section{Conclusion}

Importantly, our study suggests that the responses to contextual stimuli in China and Sri Lanka are engaged in a subtle, indirect and complex way and are far from being embedded in western-derived theories. Rather, the findings go beyond the personal argentic perspective (Bandura 2013) to investigate the underlying mechanisms that link thought processes and human action. The findings suggest a collective perspective has been incorporated into selfregulatory mechanisms.

Managers are open to cues from environmental factors that concern an appropriate mix of leadership skills and expected outcomes related to the level of their leadership skills. These cues have trickled down from an incremental reform approach in China and Sri Lanka and contributed to a hybrid form of traditional values, socialist ideology and free market principles. In the case of Sri Lanka, the socialist ideology and traditional values become an integral part of their national identity and permeate personal values, family values and community values at a very deep level, rather than just influencing political structures and systems. In the case of China, although the self-serving motives for personal survival and success seem salient on the surface, influences from a collective tradition do not become dormant. Instead, they take on a hybrid form that ascribes meaning to environmental cues set against a backdrop of contradictions, competing demands and ambivalence. Recognition of this phenomenon provides a point of entry towards analyzing the ever-changing, uncertain and messy environment that reflects working life more accurately.

This research has laid the foundation for contributions to the literature through empirical richness and meaningful contextualization. The systematic understanding of the process of self-development within China and Sri Lanka has been extended while highlighting the confluence of the multiple contextual factors that complicate managers' self-development issues within these transitional economies. Under different social, cultural and economic environments, managers working in different firms might face different challenges and adopt their unique way of self-development. Nowadays, managers in transitional economies confront both new opportunities and uncertainties. Self-development could be seen as a useful way to improve managers' capabilities to take new opportunities and minimize negative elements associated with uncertainties. Therefore, both organizations and individual managers need to encourage such self-initiated development.

\section{Acknowledgement}

The authors would like to thank the School 
of Management at the Zhejiang University, Hangzhou, China and the Department of Management Studies, Faculty of Humanities and Social Sciences at the Open University of Sri Lanka, Nawala, Sri Lanka for their support on this study.

\section{References}

AvolioBJ(2004)Examining the full rangemodel of leadership: Looking back to transform forward. In DV Day, SJ Zaccaro and SM Halpin (eds) Leadership development for transforming organizations: Grow leaders for tomorrow, 71-98. Lawrence Erlbaum \& Associates, Mahwah, NJ.

Avolio BJ \& ST Hannah (2009) Leader developmental readiness. Industrial and Organizational Psychology 2(3), 284-287.

Bandura A (2013) Social cognitive theory. In PAWV Lange, AW Kruglanski and E Higgins (eds) Handbook of theories of social psychology, 1, 349-374. SAGE, London.

Benson J, H Gospel \& Y Zhu (eds) (2013) Workforce development and skill formation in Asia. Routledge, London and New York.

Borgonjon J \& WR Vanhonacker (1994) Management training and education in the People's Republic of China. International Journal of Human Resource Management 5(2), 327-356.

Boyce LA, SJ Zaccaro \& MZ Wisecarver (2010) Propensity for self-development of leadership attributes: Understanding, predicting, and supporting performance of leader self-development. Leadership Quarterly 21, 159-178.
Day DV, MM Harrison and SM Halpin (2009) An integrative approach to leader development: Connecting adult development, identity, and expertise. Routledge, New York and London.

Garavan NT, M Mortley, P Gunnigle \& D McGuire (2002) Human resource development and work place learning: Emerging theoretical perspectives and organizational practices. Journal of European Industrial Training 26, 60-71.

Goodall K \& M Warner (2009) Management training and development in China: Laying the foundation. In M Warner and K Goodall (eds) Management training and development in China, 15-26. Routledge, London and New York.

HurtzGM \& KJWilliams (2009)Attitudinal and motivational antecedents of participation in voluntary employee development activities. Journal of Applied Psychology 94(3), 635653.

Li Y \& P Sheldon (2010) HRM lives inside and outside the firm: Employers, skill shortages and the local labour market in China. International Journal of Human Resource Management 21, 2173-2193.

Lin LH \& YL Ho (2009) Confucian dynamism, culture and ethical changes in Chinese societies: A comparative study of China, Taiwan, and Hong Kong. International Journal of Human Resource Management 20(11), 2402-2417.

NBSC (2014) China statistical yearbook, 2013. National Bureau of Statistics of China, Beijing. 
Nguyen TN, Q Truong \& D Buyens (2011) Training and firm performance in economies in transition: A comparison between Vietnam and China. Asia Pacific Business Review 17(1), 103-119.

Orvis KA \& KL Langkamer (2010) Leader selfdevelopment: A contemporary context for leader development evaluation. Leadership Quarterly 21(4), 657-674.

Reichard RJ \& SK Johnson (2011) Leader selfdevelopment as organisational strategy. Leadership Quarterly 22, 33-42.

Ren S, Y Zhu \& M Warner (2011) Human resources, higher education reform and employment opportunities for university graduates in the People's Republic of China. International Journal of Human Resource Management 22(16), 3429-3446.

Rowley C (2010) Commentary: China's chimera: Miracle or mirage in the 'middle kingdom. Asia Pacific Business Review 16(3), 269-271.

Sivalogathasan, V. (2014). Chapter 3 - Guanxi of Chinese Tourism: Recognized what they want, SHE IS MINE: How to win the hearts of Chinese Tourists?, Shakkya Publication, Sri Lanka.

Sivalogathasan,V; Xiaobo Wu: (2013), Chapter 6 - HR Issues in Family Owned Businesses: A Comparison of HRM Practices in Chinese and Sri Lankan Family Enterprises, HR Challenges: Dynamics of Value Creation and Competitiveness Though People, Published by IPM. www.ipm.lk.
Straub C (2012) Antecedents and organizational consequences of family supportive supervisor behavior: A multilevel conceptual framework for research. Human Resource Management Review 22(1), 1526.

Warner M (2010) In search of Confucian HRM: Theory and practice in greater China and beyond. International Journal of Human Resource Management 21(12), 2053-2078.

Xie YH, Y Zhu \& M Warner (2013) Exploring the reality of educated middle managers' capability and involvement in human resource management in China. International Journal of Human Resource Management 24, 1-18.

Yin RK (2011) Qualitative research from start to finish. The Guilford Press, New York.

Zhu CJ \& PJ Dowling (2000) Managing human resources in state-owned enterprises in transitional economies: A case study in the People's Republic of China. Research and Practice in Human Resource Management 8(1), 63-92.

Zhu Y \& M Warner (2013) Workforce development and skill formation in China: A new 'long march'. In J Benson, H Gospel and Y Zhu (eds) Workforce development and skill formation in Asia, 142-158. Routledge, London and New York. 